\title{
Analysis of measles-related hospitalizations in Tuscany from 2000 to 2014
}

\author{
E. BERTI ${ }^{1} \dagger$, S. SOLLAI ${ }^{1} \uparrow$, E. ORLANDINI ${ }^{2}$, L. GALLI $^{1}$, M. DE MARTINO ${ }^{1}$ AND \\ E. CHIAPPINI ${ }^{1 *}$ \\ ${ }^{1}$ Anna Meyer Children's University Hospital, Department of Health Sciences, University of Florence, Florence, \\ Italy \\ ${ }^{2}$ Tuscany Regional Government Department of Right to Health and Solidarity Policies, Information Technology \\ Section, Florence, Italy
}

Received 20 November 2015; Final revision 16 March 2016; Accepted 4 May 2016; first published online 31 May 2016

\section{SUMMARY}

To evaluate measles incidence and its relevant changes over a 14-year period (2000-2014), we analysed data from the regional hospital discharge database on children and adults hospitalized in Tuscany, Italy. A total of 181 paediatric and 413 adult cases were identified. Despite all the efforts towards regional measles elimination, we observed that the overall measles hospitalization rates for children and adults living in Tuscany globally increased from $0 \cdot 45$ to $0 \cdot 85 / 100000$ during the study period $(P=0 \cdot 001)$ showing fluctuations due to periodic measles outbreaks. Data stratified by age group showed that the hospitalization rate significantly increased in young adults over the study period, confirming an increase in susceptibility to measles in this subpopulation. Conversely, no statistically significant difference was observed in the hospitalization rate in the other age groups. However, children aged $<1$ year still exhibit the highest hospitalization rate. Pneumonia represented the most common complication in both the adult and children subsets. No death was reported. Measles still represents a public health problem, and national strategies should be implemented, focusing on emergent susceptible subsets, such as infants and young adults.

Key words: Epidemiology, measles, measles-mumps-rubella (MMR) vaccine, outbreaks, public health policy, surveillance.

\section{INTRODUCTION}

In Italy, as well as in other Western countries, outbreaks of measles continue to occur [1-4] and the objectives of the National Plan (2003-2007) for measles elimination have not been reached yet in our

\footnotetext{
* Author for correspondence: Dr E. Chiappini, Anna Meyer Children's University Hospital, Department of Sciences for Health Sciences, University of Florence, Viale Pieraccini, 24, 50100, Florence, Italy.

(Email: elena.chiappini@unifi.it)

$\dagger$ These authors contributed equally to this work.
}

country [5]. Strategies of the plan include the achievement of more than $95 \%$ coverage with one dose of measles vaccine within 2 years of life and two doses within 12 years of life; promotion of measles vaccination to susceptible populations (i.e. adolescents, healthcare and educational workers, military, 'fragile social groups' such as immigrants and nomads), and to women of childbearing age (with the objective of reaching a proportion of $<5 \%$ of susceptibles). In the present study, the incidence of measles in the paediatric and adult populations and its relevant changes over a 14-year period were evaluated to assess 
the status of measles in Tuscany in relation to the elimination target.

\section{METHODS}

\section{Study design and case definition}

A retrospective cohort study investigating children (aged $<18$ years) and adults (aged $\geqslant 18$ years) hospitalized for measles from 1 January 2000 to 31 December 2014 in 31 Tuscan hospitals was performed.

The regional hospital discharge database was consulted to select the cases, coded according to the International Classification of Disease, Ninth Revision, Clinical Modification (ICD-9-CM) system [6]. The following ICD-9-CM codes were taken into account: 055.9 (uncomplicated measles), 055.8 (complicated measles), 055.79 (measles associated with specific complications), $055 \cdot 0$ (encephalitis in measles), $055 \cdot 1$ (pneumonia in measles), $055 \cdot 2$ (otitis in measles) and $055 \cdot 71$ (keratoconjunctivitis in measles).

Hospitalized children and adults, living in Tuscany and discharged from a Tuscan hospital with a diagnosis of measles were included in the study. A double-check using any data written up on the enrolled patients was also conducted to avoid possible bias due to the inpatients being transferred between hospitals.

The number of children and adults living in Tuscany, by age group, and surveillance data about vaccination coverage for measles at age 24 months during the study period were provided by the Italian National Statistical Institute database. The study was approved by the ethics committee of the Anna Meyer Children's University Hospital in Florence, Italy.

\section{Statistical analysis}

The following characteristics of study population were analysed: age, gender, nationality, season of hospitalization of every patient, complications, median length of hospital stay and mode of discharge.

Patients were stratified by six age groups $(<1,1-4$, $5-9,10-17,18-39,>40$ years). Rates of hospitalization for measles were reported as cases $/ 100000$ children and cases/100 000 adults living in Tuscany and corresponding 95\% confidence intervals (CIs) were calculated.

Continuous variables were expressed using median values and interquartile range (IQR) and difference were evaluated using non-parametric tests (MannWhitney test). Categorical variables were analysed using the $\chi^{2}$ or the $\chi^{2}$ for trend tests (CochranArmitage test for trend). Sensitivity analyses were performed by analysing differences by measles incidence rate associated with age, gender, season of hospitalization, and complications. All significant tests were twosided. A value of $P<0.05$ was considered significant. The statistical analyses were performed using SPSS software package v. 11.5 (SPSS Inc., USA).

\section{RESULTS}

During the study period, 181 children and 413 adults were hospitalized for measles by the 31 Tuscan hospitals. Characteristics of the study population are summarized in Table 1.

Median age in the children subset was 5 (IQR 1-12) years and median age in the adult subset was 29 (IQR 23-36 years). Median age of the entire population included in the study was 23 (IQR 14-32) years. The majority of cases occurred in the 18-39 years age group (57.91\%). One quarter of the children cases were immigrants $(23 \cdot 76 \%$ ), whereas $92.25 \%$ of the adult cases were Italian. Median length of hospital stay was 4 (IQR 3-6) days in both the children and adults group.

No death was reported. The most common complications in the children group were pneumonia $(14.93 \%)$ and dehydration ( $8 \cdot 29 \%)$, followed by neurological involvement $(3 \cdot 90 \%)$ consisting of seizures and encephalopathy (Table 1). Of note, 11/27 (40.7\%) cases of pneumonia occurred in the 1-4 years group (6/11 Italians). Neurological complications occurred in the 1-4 and 10-17 years age group.

The most common complications in the adult group were pneumonia $(12 \cdot 35 \%)$ and hepatitis $(9 \cdot 44 \%)$. Rates of complications in the children and adult groups did not differ between immigrants and Italians.

\section{Measles hospitalization rate in the study population}

Children aged $<1$ year presented the highest hospitalization rate $(4 \cdot 38 / 100000,95 \%$ CI $2 \cdot 46-6 \cdot 30)$, followed by preschool children $(3 \cdot 67 / 100000,95 \%$ CI 2.79-4.55) (Fig. 1). The overall measles hospitalization rates for children and adults living in Tuscany increased over the study period, from $0 \cdot 45 / 100000$ in 2000 to $0 \cdot 85 / 100000$ in $2014\left(\chi^{2}\right.$ for trend $\left.P=0 \cdot 001\right)$. Moreover, fluctuations due to periodic measles outbreaks occurred in 2002, 2008 and 2011 (Fig. 2). During the same period, the average vaccination coverage for measles at age 24 months in Tuscany 
Table 1. Characteristics of the study population (594 children and adults hospitalized for measles in 2000-2014, in Tuscany)

\begin{tabular}{|c|c|c|c|}
\hline Characteristic & $\begin{array}{l}\text { Total population } \\
(N=594) \\
n(\%)\end{array}$ & $\begin{array}{l}\text { Children } \\
(N=181) \\
n(\%)\end{array}$ & $\begin{array}{l}\text { Adults } \\
(N=413) \\
n(\%)\end{array}$ \\
\hline \multicolumn{4}{|l|}{ Gender } \\
\hline Male & $310(52 \cdot 18)$ & $96(53 \cdot 04)$ & $199(48 \cdot 18)$ \\
\hline Female & $284(47 \cdot 82)$ & $85(46 \cdot 96)$ & $214(51 \cdot 82)$ \\
\hline \multicolumn{4}{|l|}{ Age group, years } \\
\hline$<1$ & $20(3 \cdot 37)$ & $20(11 \cdot 05)$ & \\
\hline $1-4$ & $67(11 \cdot 28)$ & $67(37 \cdot 02)$ & \\
\hline $5-9$ & $37(6 \cdot 23)$ & $37(20 \cdot 44)$ & \\
\hline $10-17$ & $57(9 \cdot 60)$ & $57(31 \cdot 49)$ & \\
\hline $18-39$ & $344(57.91)$ & & $344(83 \cdot 29)$ \\
\hline$\geqslant 40$ & $69(11 \cdot 61)$ & & $69(16 \cdot 71)$ \\
\hline \multicolumn{4}{|l|}{ Nationality } \\
\hline Italian & $519(87 \cdot 37)$ & $138(76 \cdot 24)$ & $381(92 \cdot 25)$ \\
\hline Immigrant & $75(12 \cdot 63)$ & $43(23 \cdot 76)^{*}$ & $32(7 \cdot 75)$ \\
\hline \multicolumn{4}{|l|}{ Season of hospitalization } \\
\hline Winter & $59(9 \cdot 93)$ & $20(11 \cdot 05)$ & $39(9 \cdot 44)$ \\
\hline Spring & $242(40 \cdot 74)$ & $60(33 \cdot 15)$ & $182(44 \cdot 07)$ \\
\hline Summer & $220(37 \cdot 04)$ & $65(35 \cdot 91)$ & $155(37 \cdot 53)$ \\
\hline Autumn & $73(12 \cdot 29)$ & $36(19 \cdot 89)$ & $37(8.96)$ \\
\hline \multicolumn{4}{|l|}{ Complications } \\
\hline Uncomplicated & $381(64 \cdot 14)$ & $118(65 \cdot 19)$ & $263(63 \cdot 68)$ \\
\hline Dehydration & $24(4 \cdot 04)$ & $15(8 \cdot 29)$ & $9(2 \cdot 18)$ \\
\hline Keratoconjunctivitis & $16(2 \cdot 69)$ & $4(2 \cdot 21)$ & $12(2 \cdot 91)$ \\
\hline Asthma & $8(1.35)$ & $3(1 \cdot 66)$ & $5(1 \cdot 21)$ \\
\hline Pneumonia & $78(13 \cdot 14)$ & $27(14 \cdot 93)$ & $51(12 \cdot 35)$ \\
\hline Respiratory failure & $17(2 \cdot 86)$ & $4(2 \cdot 21)$ & $13(3 \cdot 15)$ \\
\hline Bacterial sepsis & $5(0 \cdot 84)$ & None & $5(1 \cdot 21)$ \\
\hline Pancreatitis & $4(0 \cdot 67)$ & $2(1 \cdot 10)$ & $2(0 \cdot 48)$ \\
\hline Hepatitis & $40(6 \cdot 73)$ & $1(0 \cdot 55)$ & $39(9 \cdot 44)$ \\
\hline Seizures & $9(1.52)$ & $5(2 \cdot 76)$ & $4(0 \cdot 97)$ \\
\hline Encephalopathy & $12(2 \cdot 02)$ & $2(1 \cdot 10)$ & $10(2 \cdot 42)$ \\
\hline Deaths & None & None & None \\
\hline Median length of hospital stay, days (IQR) & $4(3-6)$ & $4(3-6)$ & $4(3-6)$ \\
\hline
\end{tabular}

IQR, Interquartile range.

* Immigrant children's age groups: <1 year: $6 / 20(30 \cdot 0 \%) ; 1-4$ years: $22 / 67(32 \cdot 8 \%) ; 5-9$ years: 8/37 $(21 \cdot 6 \%) ; 10-17$ years $5 / 57$ $(8 \cdot 8 \%)$.

gradually increased from $78 \cdot 5 \%$ in 2000 to a maximum value of $93 \cdot 1 \%$ in $2010\left(\chi^{2}\right.$ for trend $\left.P<0 \cdot 001\right)$, then decreased to $89 \cdot 3 \%$ in 2014 ( $\chi^{2}$ for trend $P<0 \cdot 001$ ) (Fig. 2). Data stratified by age showed that over the study period the hospitalization rate significantly increased in the 18-39 years age group $\left(\chi^{2}\right.$ for trend $P<0.001)$. Conversely, no statistically significant difference was observed in the hospitalization rate in the other age groups.

\section{DISCUSSION}

The present report analyses changes in measles hospitalization rates in the paediatric and adult populations in Tuscany over a 14 -year period, using regional discharge data.

Despite all the efforts towards regional measles elimination [5], we observed that the overall measles hospitalization rates for children and adults living in Tuscany globally increased from $0 \cdot 45$ to $0 \cdot 85 / 100000$ during the study period, showing fluctuations due to periodic measles outbreaks. These findings are not completely unexpected since an optimal vaccination coverage has not yet been achieved: average vaccination coverage for measles at age 24 months in Tuscany was $89 \cdot 3 \%$ in 2014 , not reaching the measles control goal of $>90-95 \%$. Moreover, this value which is an expression of a progressive decrease in 


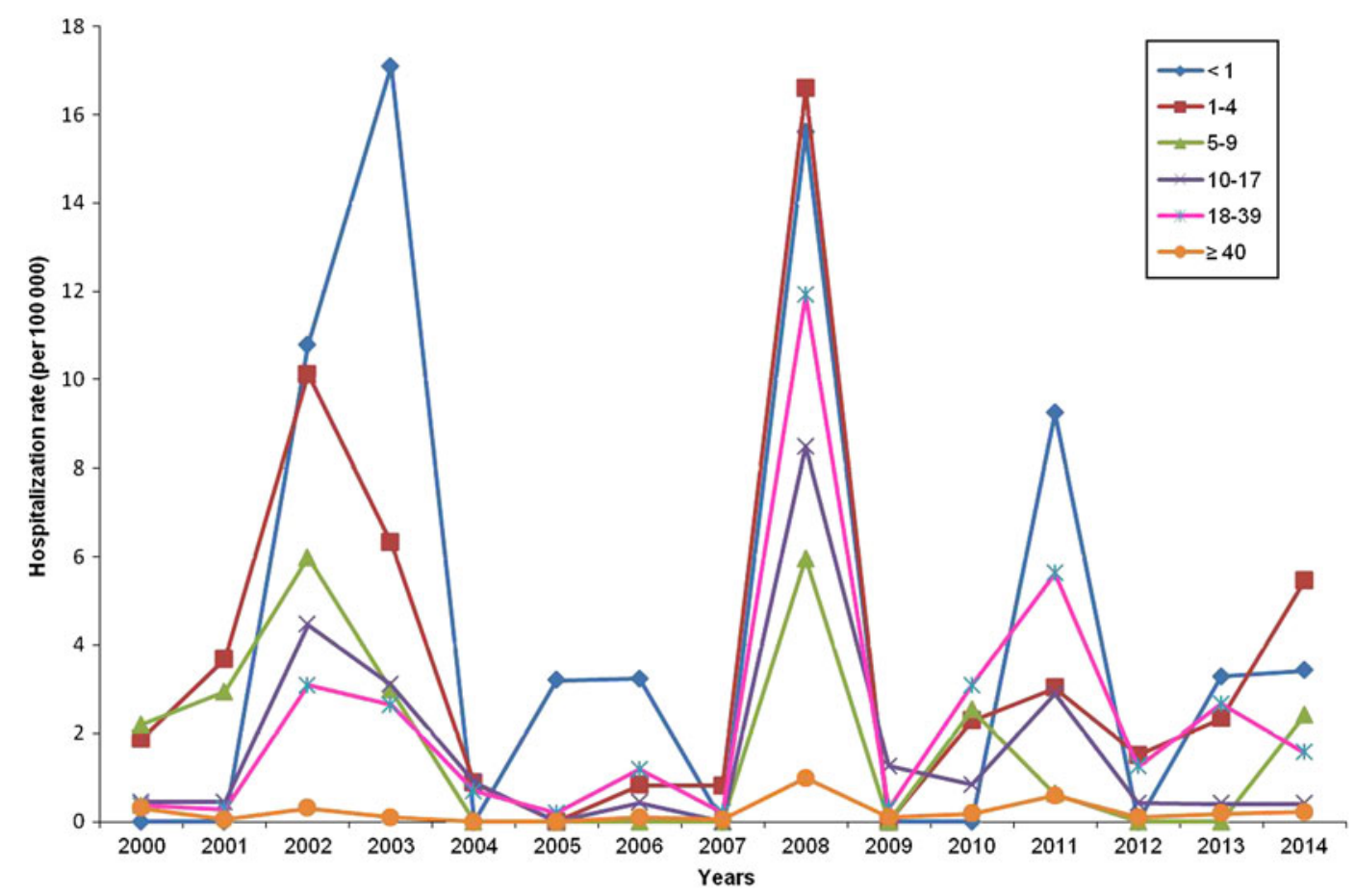

Fig. 1. Hospitalization rate (per 100 000) for measles in Tuscany over the study period (2000-2014), stratified by age group.

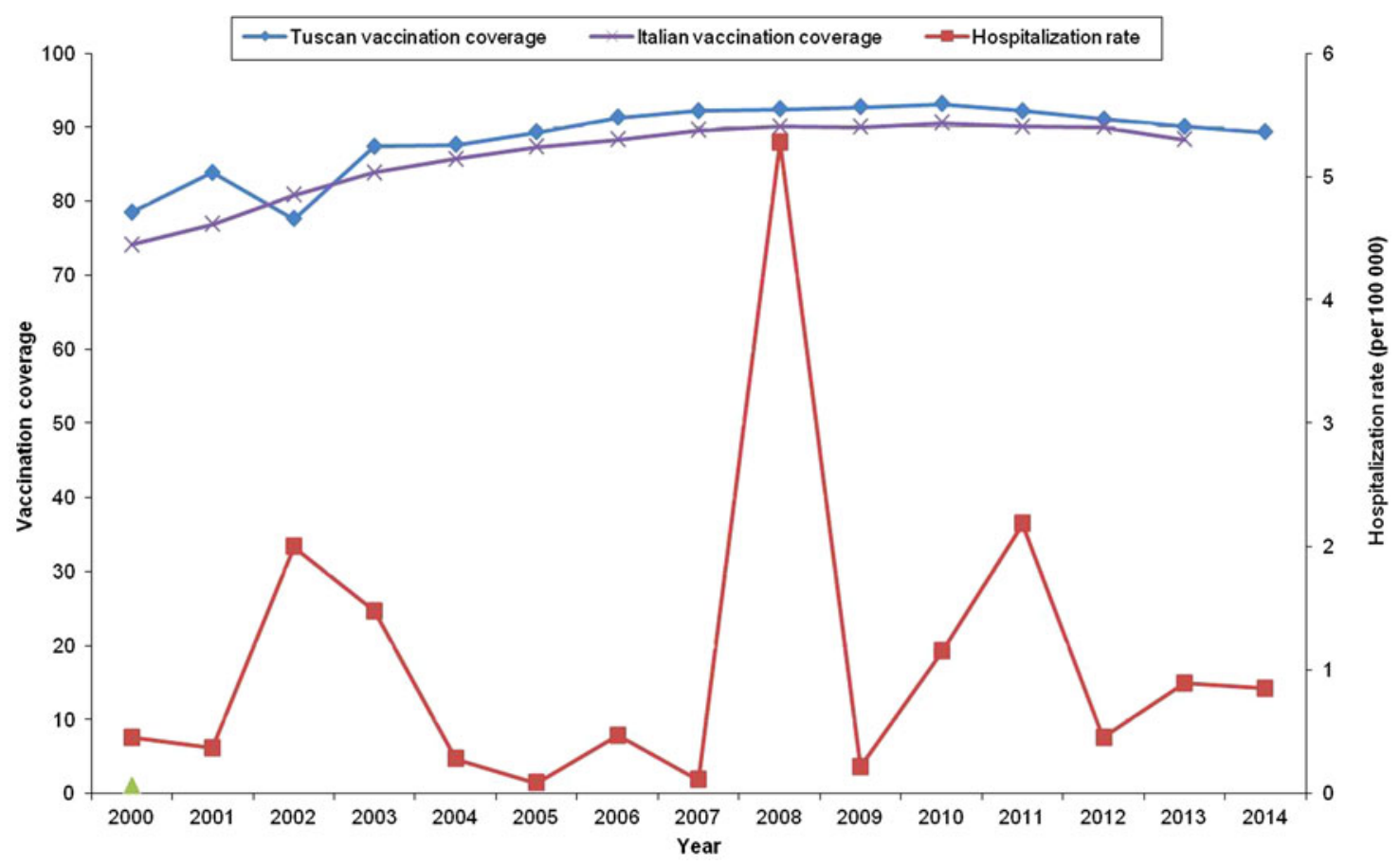

Fig. 2. Hospitalization rate (per 100000 ) and vaccination coverage (\%) for measles in Tuscany and in Italy over the study period (2000-2014).

vaccination coverage was noted in the last years, leading to silent increasing of susceptible subjects [7]. This phenomenon could be partly related to growing concerns regarding the safety of vaccines, encouraged by anti-vaccination movements that are spreading in
European countries, and underlines the importance of strongly reinforcing public awareness on the safety and efficacy of measles vaccine [8]. In a recent crosssectional study conducted in Italy, the role played by the internet [odds ratio (OR) $19 \cdot 8, P=0 \cdot 001]$ and the 
large number of children in a family (OR 7·3, $P \leqslant 0 \cdot 001$ ) were the factors more associated with being unvaccinated [9]. Some authors have suggested a suboptimal vaccination coverage in migrant populations may be related to language, information and administrative barriers in accessing routine immunization and health services for these vulnerable subjects [10], but in our study only one quarter of paediatric cases was in immigrant children and the complication rate did not differ between Italians and immigrants. This confirms what we expected, as vaccinations in Tuscany (as in Italy) are offered for free to all residents. However, considering that our study is based on a regional electronic database, we do not have sufficient and detailed information regarding the nationality of the parents to evaluate differences between Italians and 'second-generation' immigrant children.

Our data confirm that large measles epidemics continue to occur in Italy, although differences between regions have been described $[11,12]$. These discrepancies can be explained not only by differences in current regional measles-mumps-rubella vaccination coverage levels [13], but also by underreporting, especially in southern regions [11, 12]. Recently measles has re-emerged in other European countries which experienced large outbreaks in the same years as observed in Tuscany [1]. In the United States a record number of 668 measles cases from 27 states was reported to CDC's National Center for Immunization and Respiratory Diseases (NCIRD) in 2014, which was the greatest number of cases since measles elimination was documented in the United States in 2000 [2].

Our data, described in Table 2, show that the hospitalization rate significantly increased in young adults over the study period, confirming an increase in susceptibility to measles $[4,14-17]$. Considering that globally measles incidence is usually expressed as cases per million population (with a goal of $<5$ cases/million by $2015)$, rates of hospitalized measles cases $(2 \cdot 19 / 100000$ $=22 /$ million) are quite high and suggest high rates of transmission in the community, indicating that this is just the tip of the iceberg. In fact the current immunization programme has left a window of vulnerability for young adults who have never been exposed to measles, have never been vaccinated or were vaccinated but did not respond. Moreover, it must be considered that vaccine-induced immunity may decline over time. It has been described that subjects who received their last dose of measles vaccine more than 10 years previously have a small but significantly increased risk of becoming infected compared to people recently vaccinated, suggesting that measles vaccination does not guarantee a lifelong immunity $[1,18]$. Additionally, it should be taken into account that the role of 'natural boosting' is declining [7, 19]. Del Fava and colleagues, in their study conducted with the aim of analysing the effects of a large vaccination campaign in Tuscany, accurately identified a large pocket of susceptible individuals aged about 13-14 years in 2005-2006, and a larger group of weakly immune individuals aged 20 years in 2005-2006. These authors concluded that these cohorts represent possible targets for further interventions towards measles elimination [7].

Low vaccination coverage in healthcare workers (HCWs) may have contributed to the spread of measles in healthcare settings during the outbreaks, as previously reported in Italy [20, 21]. Interestingly, in a recent cross-sectional survey performed in six Florentine hospitals, among those HCWs reporting no history of disease, $52.8 \%$ declared having been immunized against measles, and when considering potentially susceptible HCWs (without history of disease or vaccination and without serological confirmation), less than half of them felt at risk for the concerned diseases and only $<30 \%$ would undergo immunization. Lack of an active offer of vaccines was considered to be one of the main reasons of the relatively low coverage [22]. Unfortunately, no data about nosocomial transmission cases were available in our database to allow us to analyse this mode of transmission.

As in other Western countries [1, 4, 17], children aged $<1$ year presented the highest hospitalization rate. This is possibly related to the actual vaccination policy (the first measles vaccine dose is administered at age 12 months), but also to the high susceptibility of adult contacts which may constitute an important reservoir for transmission. Moreover, the weaning immunity in women of childbearing age does not allow the indirect protection of infants through maternal antibodies transferred across the placenta. Although immunization programmes have led to a marked reduction in measles complication rates, still pneumonia represents the main complication in both children and adults, as reported above [23-25].

Our study may have some limitations. Although the ICD-9 discharge diagnosis code is an accurate method to monitor the occurrence of some diseases [26-30], some diagnoses may have been inadvertently excluded or misattributed. However, it is unlikely that this possible bias changed our final results. 
Table 2. Yearly absolute number of cases and hospitalization ratel100 000 for measles (95\% CI) by age group in Tuscan children and adults, 2000-2014

\begin{tabular}{|c|c|c|c|c|c|c|c|}
\hline & $<1$ year & $1-4$ years & $5-9$ years & $10-17$ years & 18-39 years & $\geqslant 40$ years & Overall \\
\hline \multicolumn{8}{|l|}{2000} \\
\hline Cases $(n)$ & 0 & 2 & 3 & 1 & 4 & 6 & 16 \\
\hline Rate $(95 \% \mathrm{CI})$ & & $1 \cdot 9(0-4 \cdot 48)$ & $2 \cdot 2(0-4 \cdot 67)$ & $0 \cdot 4(0-1 \cdot 31)$ & $0.4(0 \cdot 01-0.73)$ & $0 \cdot 3(0 \cdot 06-0 \cdot 55)$ & $0 \cdot 45(0 \cdot 23-0 \cdot 67)$ \\
\hline \multicolumn{8}{|l|}{2001} \\
\hline Cases $(n)$ & 0 & 4 & 4 & 1 & 3 & 1 & 13 \\
\hline Rate $(95 \% \mathrm{CI})$ & & $3 \cdot 7(0 \cdot 07-7 \cdot 28)$ & $2 \cdot 9(0 \cdot 06-5 \cdot 82)$ & $0 \cdot 4(0-1 \cdot 30)$ & $0.3(0.04-0.60)$ & $0 \cdot 1(0-0 \cdot 15)$ & $0 \cdot 37(0 \cdot 17-0 \cdot 57)$ \\
\hline \multicolumn{8}{|l|}{2002} \\
\hline Cases $(n)$ & 3 & 11 & 8 & 10 & 32 & 6 & 70 \\
\hline Rate $(95 \% \mathrm{CI})$ & $10 \cdot 8(0-22 \cdot 99)$ & $10 \cdot 1(4 \cdot 14-16 \cdot 09)$ & $6 \cdot 0(1 \cdot 84-10 \cdot 14)$ & $4 \cdot 5(1 \cdot 70-7 \cdot 22)$ & $3 \cdot 1(2 \cdot 02-4 \cdot 16)$ & $0 \cdot 3(0 \cdot 06-0 \cdot 55)$ & $2(1 \cdot 53-2 \cdot 47)$ \\
\hline \multicolumn{8}{|l|}{2003} \\
\hline Cases $(n)$ & 5 & 7 & 4 & 7 & 27 & 2 & 52 \\
\hline Rate $(95 \% \mathrm{CI})$ & $17 \cdot 1(2 \cdot 11-32 \cdot 07)$ & $6 \cdot 3(1 \cdot 64-11 \cdot 00)$ & $3 \cdot 0(0 \cdot 06-5 \cdot 90)$ & $3 \cdot 1(0 \cdot 80-5 \cdot 40)$ & $2 \cdot 6(1 \cdot 64-3 \cdot 64)$ & $0 \cdot 1(0-0 \cdot 24)$ & $1.48(1 \cdot 08-1 \cdot 88)$ \\
\hline \multicolumn{8}{|l|}{2004} \\
\hline Cases $(n)$ & 0 & 1 & 0 & 2 & 7 & 0 & 10 \\
\hline Rate $(95 \% \mathrm{CI})$ & & $0 \cdot 9(0-2 \cdot 57)$ & & $0 \cdot 9(0-2 \cdot 10)$ & $0 \cdot 7(0 \cdot 18-1 \cdot 19)$ & & $0 \cdot 28(0 \cdot 11-0 \cdot 45)$ \\
\hline \multicolumn{8}{|l|}{2005} \\
\hline Cases $(n)$ & 1 & 0 & 0 & 0 & 2 & 0 & 3 \\
\hline Rate $(95 \% \mathrm{CI})$ & $3 \cdot 2(0-9 \cdot 47)$ & & & & $0 \cdot 2(0-0 \cdot 47)$ & & $0 \cdot 08(0-0 \cdot 18)$ \\
\hline \multicolumn{8}{|l|}{2006} \\
\hline Cases $(n)$ & 1 & 1 & 0 & 1 & 12 & 2 & 17 \\
\hline Rate $(95 \% \mathrm{CI})$ & $3 \cdot 2(0-9 \cdot 57)$ & $0 \cdot 8(0-2 \cdot 44)$ & & $0 \cdot 4(0-1 \cdot 28)$ & $1 \cdot 2(0 \cdot 52-1 \cdot 86)$ & $0 \cdot 1(0-0 \cdot 23)$ & $0 \cdot 47(0 \cdot 25-0 \cdot 69)$ \\
\hline \multicolumn{8}{|l|}{2007} \\
\hline Cases $(n)$ & 0 & 1 & 0 & 0 & 2 & 1 & 4 \\
\hline Rate $(95 \% \mathrm{CI})$ & & $0 \cdot 8(0-2 \cdot 39)$ & & & $0 \cdot 2(0-0 \cdot 48)$ & $0 \cdot 1(0 \cdot 05-0 \cdot 14)$ & $0 \cdot 11(0 \cdot 00-0 \cdot 22)$ \\
\hline \multicolumn{8}{|l|}{2008} \\
\hline Cases $(n)$ & 5 & 21 & 9 & 20 & 118 & 21 & 192 \\
\hline Rate $(95 \% \mathrm{CI})$ & $15 \cdot 6(1 \cdot 93-29 \cdot 29)$ & $16 \cdot 6(9 \cdot 49-23 \cdot 68)$ & $6 \cdot 0(2 \cdot 06-9 \cdot 85)$ & $8 \cdot 5(4 \cdot 77-12 \cdot 20)$ & $11.9(9 \cdot 76-14.06)$ & $1 \cdot 0(0 \cdot 56-1 \cdot 40)$ & $5 \cdot 28(4 \cdot 53-6 \cdot 02)$ \\
\hline \multicolumn{8}{|l|}{2009} \\
\hline Cases $(n)$ & 0 & 0 & 0 & 3 & 3 & 2 & 8 \\
\hline Rate $(95 \% \mathrm{CI})$ & & & & $1 \cdot 3(0-2 \cdot 69)$ & $0 \cdot 3(0-0 \cdot 65)$ & $0 \cdot 1(0-0 \cdot 22)$ & $0 \cdot 22(0 \cdot 07-0 \cdot 37)$ \\
\hline \multicolumn{8}{|l|}{2010} \\
\hline Cases $(n)$ & 0 & 3 & 4 & 2 & 30 & 4 & 43 \\
\hline Rate $(95 \% \mathrm{CI})$ & & $2 \cdot 3(0-4 \cdot 86)$ & $2 \cdot 5(0 \cdot 05-5 \cdot 02)$ & $0 \cdot 8(0-1 \cdot 99)$ & $3 \cdot 1(1 \cdot 98-4 \cdot 19)$ & $0 \cdot 2(0-0 \cdot 36)$ & $1 \cdot 15(0 \cdot 81-1 \cdot 50)$ \\
\hline \multicolumn{8}{|l|}{2011} \\
\hline Cases $(n)$ & 3 & 4 & 1 & 7 & 54 & 13 & 82 \\
\hline Rate $(95 \% \mathrm{CI})$ & $9 \cdot 2(0-19 \cdot 69)$ & $3 \cdot 0(0 \cdot 06-5 \cdot 98)$ & $0 \cdot 6(0-1 \cdot 85)$ & $2 \cdot 9(0 \cdot 75-5 \cdot 04)$ & $5 \cdot 6(4 \cdot 12-7 \cdot 12)$ & $0 \cdot 6(0 \cdot 27-0 \cdot 90)$ & $2 \cdot 19(1 \cdot 71-2 \cdot 66)$ \\
\hline
\end{tabular}




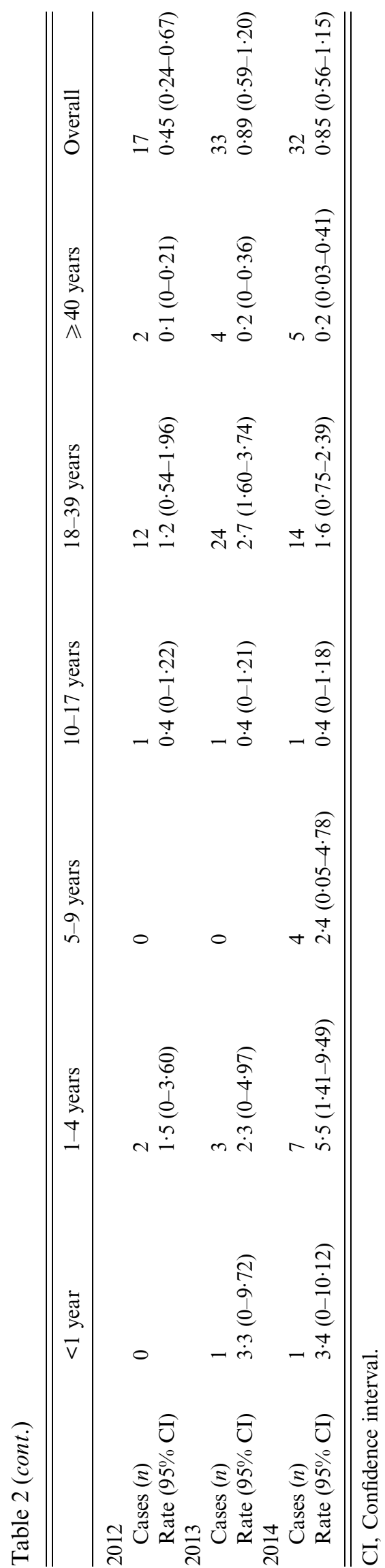

Another limitation of our study is represented by the challenge to estimate the actual incidence rates of the disease, as we could only analyse hospitalization data. Excluding cases of mild measles that did not require hospital care may have led to a slight overestimation of complication incidence, and to an underestimation of measles incidence rates. The Italian National Surveillance System does not register the vaccination coverage after the second dose of vaccination (which is recommended at 5-6 years), so we were unable to analyse the actual adherence to the vaccination schedule over time. Additionally, in our analysis we could not consider the vaccination status of each case included, as these data were not available. These kind of information would have been helpful to evaluate the waning immunity in adolescents and young adults, and to compare the risk of complicated disease in unvaccinated and vaccinated subjects. Moreover, we considered anyone born in Italy as 'Italian', regardless of immigration status of parents. It would have been interesting to evaluate hypothetical differences between Italian and 'second-generation' immigrant children but we did not have sufficient and detailed information regarding the nationality of the parents of the cases reported in our regional database.

\section{CONCLUSIONS}

Measles still represents a serious public health problem worldwide [1-4], highlighting that the current approach is not effective in interrupting the circulation of the virus. Although the Tuscan region has always represented excellence in the field of prevention in Italy, in our analysis we evidenced a marked decline in immunization coverage rates in the last years, leading to new outbreaks of measles in this area, as in the rest of Italy and Europe. High vaccination coverage $(\geqslant 95 \%)$ with two doses of measles vaccine in all population groups is crucial to elimination. Vaccination coverage, even for a second dose, should be improved with tailored strategies, especially with respect to young adults and adolescents, with special consideration for women of childbearing age. Every opportunity should be used to reach children with routine vaccination and to present adolescents and adults with the option of checking their vaccination status and receiving vaccinations that they may have missed.

\section{DECLARATION OF INTEREST}

None. 


\section{REFERENCES}

1. European Centre for Disease Prevention and Control. Measles surveillance data (http://ecdc.europa.eu/en/ healthtopics/measles/epidemiological_data/pages/annual_ epidemiological_reports.aspx). Accessed 20 August $201 \overline{5}$.

2. Centers for Diseases Control and Prevention. Measles cases and outbreaks (http://www.cdc.gov/measles/ cases-outbreaks.html). Accessed 20 August 2015.

3. Perry RT, et al. Centers for Disease Control and Prevention (CDC). Progress toward regional measles elimination-worldwide, 2000-2013. Morbidity and Mortality Weekly Report 2014; 63: 1034-8.

4. Chiew M, et al. Australian vaccine preventable disease epidemiological review series: measles 2000-2011. Communicable Diseases Intelligence Quarterly Report 2015; 39: E1-9.

5. Presidency of the Council of Ministers. Rep. N. 66/ State-Regions Conference of 23 March 2011. Italian national plan for the elimination of measles and congenital rubella (PNEMoRc) 2010-2015 [in Italian] (http://www. epicentro.iss.it/focus/morbillo/PianoEliminazioneMorbillo RosoliaCongenita2010-2015.asp). Accessed 20 August 2015.

6. Italian Health Ministry. Ministerial Act, 28 December 1991. Hospital discharge form creation. Gazzetta Ufficiale 17 January 1992, number 13.

7. Del Fava E, et al. Towards measles elimination in Italy: monitoring herd immunity by Bayesian mixture modelling of serological data. Epidemics 2012; 4: 124-131.

8. Zahn M. Just when you think you know someone: the evolving epidemiologies of measles and pertussis. Current Opinion in Pediatrics 2016; 28: 101-106.

9. Restivo $\mathbf{V}$, et al. Factors associated with poor adherence to MMR vaccination in parents who follow vaccination schedule. Human Vaccines \& Immunotherapeutics 2015; 11: $140-145$.

10. Williams GA, et al. Measles among migrants in the European Union and the European Economic Area. Scandinavian Journal of Public Health 2016; 44: 6-13.

11. Filia A, et al. Measles in Italy, July 2009 to September 2010. Eurosurveillance 2011; 16: pii $=19925$.

12. Filia A, et al. Analysis of national measles surveillance data in Italy from October 2010 to December 2011 and priorities for reaching the 2015 measles elimination goal. Eurosurveillance 2013; 18: pii $=20480$.

13. Italian Health Ministry. Vaccine coverage in children (http://www.salute.gov.it/imgs/C_17_pagineAree_811_ listaFile_itemName_11_file.pdf). Accessed 20 August 2015.

14. Bechini A, et al. Progress in the elimination of measles and congenital rubella in Central Italy. Human Vaccines \& Immunotherapeutics 2013; 9: 649-656.

15. Bassetti M, et al. Measles outbreak in adults in Italy. Infezioni in Medicina 2011; 19: 16-19.

16. Celesia BM, et al. A measles outbreak in Catania, Sicily: the importance of high vaccination coverage and early notification of cases for health and economic reasons. Infezioni in Medicina 2014; 22: 222-226.
17. Pezzotti P, et al. Measles outbreak in the Lazio region of Italy: surveillance and impact on emergency departments and hospitalizations. Annali di Igiene 2013; 25: 299-309.

18. Jones $\mathbf{J}$, et al. Lack of measles transmission to susceptible contacts from a health care worker with probable secondary vaccine failure - Maricopa County, Arizona, 2015. Morbidity and Mortality Weekly Report 2015; 64: 832-833.

19. Bechini A, et al. Progress towards measles and rubella elimination in Tuscany, Italy: the role of population seroepidemiological profile. European Journal of Public Health 2012; 22: 133-139.

20. Campagna M, et al. Exanthemic diseases (measles, chickenpox, rubella and parotitis). Focus on screening and health surveillance of health workers: results and perspectives of a multicenter working group. Giornale Italiano di Medicina del Lavoro ed Ergonomia 2010; 32: 298-303.

21. Porru S, et al. Susceptibility to varicella-zoster, measles, rosacea and mumps among health care workers in a Northern Italy hospital. Giornale Italiano di Medicina del Lavoro ed Ergonomia 2007; 29: 407-409.

22. Taddei $\mathbf{C}$, et al. Attitude toward immunization and risk perception of measles, rubella, mumps, varicella, and pertussis in health care workers working in 6 hospitals of Florence, Italy 2011. Human Vaccines \& Immunotherapeutics 2014; 10: 2612-2622.

23. American Academy of Pediatrics Committee on Infectious Diseases. Measles. Red Book ${ }^{\circledR}$ : 2015 Report of the Committee on Infectious Diseases, 30th edn (http://sitemaster.solutions.aap.org/DocumentLibrary/ 2015RedBookMeasles.pdf).

24. Roush SW, Murphy TV; Vaccine-Preventable Disease Table Working Group. Historical comparisons of morbidity and mortality for vaccine-preventable diseases in the United States. Journal of the American Medical Association 2007; 298: 2155-2163.

25. Centers for Disease Control and Prevention. Epidemiology and prevention of vaccine-preventable diseases, 13th edn. In: Hamborsky J, Kroger A, Wolfe S, eds. Washington D.C.: Public Health Foundation, 2015.

26. Meregaglia M, et al. Parent 'cocoon' immunization to prevent pertussis-related hospitalization in infants: the case of Piemonte in Italy. Vaccine 2013; 31: 1135-1137.

27. Quan H, Parsons GA, Ghali WA. Validity of procedure codes in international classification of disease revision, clinical modification administrative data. Medical Care 2004; 42: 801-809.

28. Chiappini E, et al. Increasing incidence of tuberculosis in Tuscan youth, 1997 to 2011. Pediatric Infectious Disease Journal 2013; 32: 1289-1291.

29. Berti E, et al. Pertussis is still common in a highly vaccinated infant population. Acta Paediatrica 2014; 103: 846-849.

30. Bonsignori F, et al. Hospitalization rates for complicated and uncomplicated chickenpox in a poorly vaccined pediatric population. Infection 2007; 35: $444-450$. 